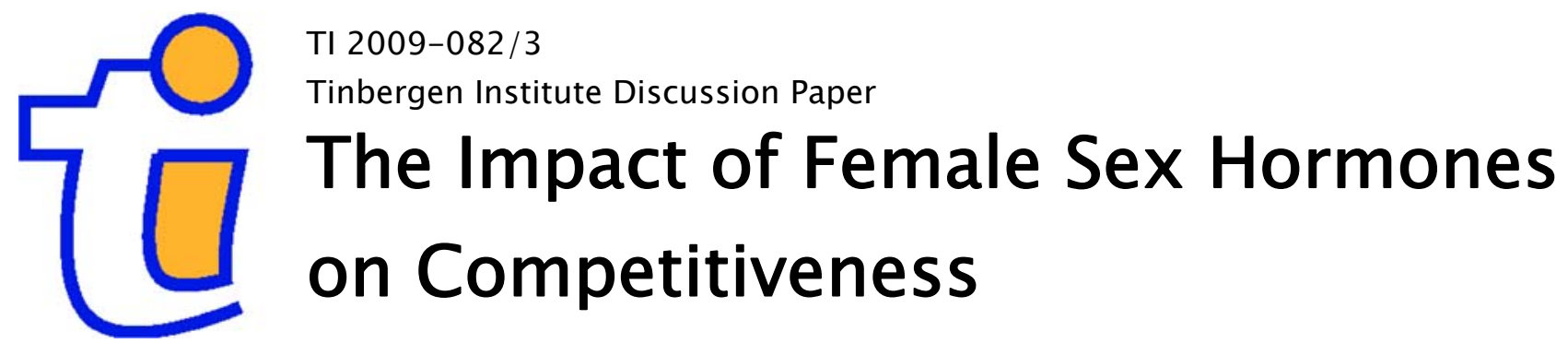

Thomas Buser

School of Economics, University of Amsterdam, and Tinbergen Institute. 


\section{Tinbergen Institute}

The Tinbergen Institute is the institute for economic research of the Erasmus Universiteit Rotterdam, Universiteit van Amsterdam, and Vrije Universiteit Amsterdam.

Tinbergen Institute Amsterdam

Roetersstraat 31

1018 WB Amsterdam

The Netherlands

Tel.: +31(0)205513500

Fax: $+31(0) 205513555$

Tinbergen Institute Rotterdam

Burg. Oudlaan 50

3062 PA Rotterdam

The Netherlands

Tel.: + $31(0) 104088900$

Fax: $+31(0) 104089031$

Most TI discussion papers can be downloaded at http://www.tinbergen.nl. 


\title{
The impact of female sex hormones on competitiveness
}

\author{
Thomas Buser*
}

\begin{abstract}
We use fluctuations of female sex hormones occurring naturally over the menstrual cycle or induced by hormonal contraceptives to determine the importance of sex hormones in explaining gender differences in competitiveness. Participants in a laboratory experiment solve a simple arithmetics task first under a piece rate and then under a competitive tournament scheme. Subjects can then choose which compensation scheme to apply in a third round. We find that sex hormones have a strong effect on whether women select into the competitive environment. The observed patterns are consistent with a negative impact especially of progesterone on competitiveness and our results therefore provide a partial biological explanation for gender differences in competitiveness. We consider three possible indirect pathways through which sex hormones could affect competitiveness: via an impact on risk aversion, via an impact on performance, and via an impact on overconfidence. None of these hold up to the data and we conclude that sex hormones have a more direct impact on competitiveness.
\end{abstract}

\footnotetext{
${ }^{*}$ University of Amsterdam, School of Economics. This version: September 2009. I am indebted to Hessel Oosterbeek for his many suggestions and his invaluable support. I also thank Erik Plug, Joep Sonnemans, Pieter Gautier and conference participants at ABEE for their valuable comments. I would further like to thank Nadine Ketel, Jose Rosero Moncayo, and Lygia Cesar for great research assistance in the lab. I gratefully acknowledge financial support from the University of Amsterdam through the Speerpunt Behavioural Economics and thank CREED for letting me use their lab.
} 


\section{Introduction}

The literature on the impact of gender on economic decision making is extensive and gender differences in preferences, particularly concerning competitiveness, are often identified as a potential source of the persisting wage gap between men and women. The potential importance of gender differences in competitiveness as a cause of the gender wage gap becomes clear when one considers to which extent the allocation of top executive jobs is skewed in favour of men. ${ }^{1}$ Gender discrimination and conflicts between the long hours worked in such careers and family life are often identified as potential causes. More recently, the experimental economics literature has identified an additional explanation: women tend to dislike competition while men actively seek it. Promotions and wage increases are often conditional on prevailing in tournament-like competition and if less women enter competitive environments, less will come out on top. The aim of this paper is to determine whether biological factors, in particular differences in the hormonal balance between women and men, can help explain the gender differences in competitiveness observed by a growing number of experimental studies.

Most of these experimental studies have subjects perform a simple task whereby the compensation scheme is varied between a non-competitive piece rate and a competitive tournament scheme. Overall, when subjects are given the choice of whether or not to enter the tournament, women tend to opt out while the majority of men chooses to enter. Niederle and Vesterlund (2007), using a simple maths task for which no gender differences in performance are observed, find that 73 percent of men prefer the tournament while only 35 percent of women choose to compete. This leads to many poorly performing males hurting their payoffs by entering the tournament while many well-performing women lose out by inefficiently shying away from it. Datta Gupta et al. (2005) obtain similar results while also concluding that women, but not men, are primarily influenced by their degree of risk aversion when picking between piece rate and tournament compensation schemes. Gneezy et al. (2003) moreover find that men significantly increase effort when the compensation scheme for a task becomes more competitive while women show no reaction. ${ }^{2}$

Whether this divergence in attitudes towards competition is mostly caused by innate factors or rather a consequence of upbringing and culture is still largely an open question. There are only a few studies in economics investigating potential biological reasons for (gender) differences in decision making, often pointing towards differences in the hormonal balance as a source of diverging attitudes. Burnham (2007) finds that higher testosterone levels are associated with a higher probability of rejection in the ultimatum game and Apicella et al. (2008) find testosterone to be correlated with financial risk taking. Treating subjects with nasal sprays, Kosfeld et al. (2005) show that the hormone Oxytocin,

\footnotetext{
${ }^{1}$ Using a dataset containing information on the five highest paid executives in large US corporations for the years 1992-97, Bertrand and Hallock (2001) find that the representation of women reaches a mere 2.5 percent.

${ }^{2}$ See Croson and Gneezy (2009) for a review of gender differences in lab and field experiments covering the areas of risk aversion, competitiveness, and social preferences.
} 
which plays a central role in mother child bonding and sexual intimacy ${ }^{3}$, significantly increases giving in the trust game. ${ }^{4}$ Sapienza et al. (2009) using a large sample of MBA students, find that testosterone levels are positively correlated with risk seeking and that the gender gap in the likelihood of seeking out a career in finance disappears when controlling for current and prenatal testosterone levels. Treating a sample of post-menopausal women with high doses of testosterone and oestrogen, Zethraeus et al. (2009), on the other hand, find no impact of hormonal levels in a range of games measuring altruism, trust, fairness and risk aversion. To our knowledge, there are no studies looking at the link between biological factors and competitiveness.

On the other hand, the economic literature also provides some evidence pointing towards nurture rather than nature being at the root of gender differences in competitiveness. Gneezy et al. (2008) investigate the impact of culture by conducting the same experiment, in which participants can choose between piece rate and tournament compensation for throwing balls into a basket, both with subjects stemming from a fiercely patriarchal society (the Maasai of Tanzania) and subjects from a matrilineal society (the Khasi of India). While the Maasai exhibit the same gender gap in competitiveness found in Western societies, the roles are reversed in the Khasi sessions: Khasi women are even slightly more competitive than Maasai men. Letting teenage subjects from all-girls, all-boys, and co-educational schools choose between piece-rate and tournament compensation for solving mazes, Booth and Nolen (2009a) find that girls attending single-sex schools are significantly more likely to choose the tournament. $^{5}$

In our experiment, we make use of hormonal fluctuations - naturally occurring over the menstrual cycle or induced by contraceptives - to analyse to what extent preferences concerning self-selection into competitive environments are affected by female sex hormones and to find out how important this phenomenon is as a determinant of gender differences. If competitiveness is indeed related to female sex hormones, we would expect it to fluctuate in sync with hormone levels; the gender gap widening when hormone concentrations in the body are high and narrowing when they are low. Such a finding would support the hypothesis that innate differences can explain a significant part of the gender gap in competitiveness. If the divergence between the competitive behaviour of men and women is due solely to nurture, on the other hand, we would expect to observe no hormonal effects.

The impact of the menstrual cycle on economic decision making has so far only been analysed in the context of sealed bid auctions. Analysing bidding behaviour in first-price auctions, Chen et al. (2009) find that the gender gap in overbidding - women overbid significantly more than men - fluctuates

\footnotetext{
${ }^{3}$ See e.g. Uvnäs-Moberg (1998) and Carmichael et al. (1994).

${ }^{4}$ Baumgartner et al. (2008), using the same methodology, further show that contrary to the controls, subjects treated with oxytocin do not decrease trusting even after their trust has been breached repeatedly. Fehr (2009) reviews further evidence of biological and other factors influencing trusting behaviour.

${ }^{5}$ In Booth and Nolen (2009b), the authors similarly show that the gender gap in risk aversion - girls are 36 percent less likely than boys to choose a risky gamble over a safe option - disappears completely for girls being raised in single-sex schools.
} 
over the menstrual cycle. The authors conclude that most of this variation is due to contraceptive users but this is based on a very small number of subjects as they have information on contraceptive usage only for part of their sample. In a replication, Pearson and Schipper (2009) find significant fluctuations in bidding behaviour that are at odds with the findings of Chen et al. (2009). They suggest an evolutionary explanation according to which women bid higher during the more fertile phases of their cycle. It is doubtful, however, whether bidding in auctions is a good analogy for behaviour in competitive or risky situations. Moreover, the auction design, created with the aim of measuring ambiguity aversion (Chen et al., 2007), is complex and it is unclear what is really being picked up by the bidding behaviour of subjects. ${ }^{6}$

We divide subjects into groups of four and let them perform the simple task of solving a series of additions of five two-digit numbers, first under a piece-rate compensation and then under a tournament scheme. Under the tournament, the payment per correct answer for the best performing member of the group increases fourfold while the rest of the group are left empty-handed. After having received feedback on their absolute but not on their relative performance in the first two rounds, subjects decide themselves which of the two compensation schemes they wish to apply to a third round. We find that the likelihood of selecting into the tournament fluctuates strongly and significantly over the menstrual cycle and with the intake of hormonal contraceptives. Moreover, these fluctuations follow the predicted pattern with subjects being significantly less competitive - and the gender gap thus widening - in times of high concentrations of sex hormones in the body. Making use of the diverging fluctuations of oestrogen and progesterone over the menstrual cycle, we conclude that this is mainly due to the effect of progesterone. We consider three possible indirect pathways for the effect of hormones on competitiveness: via an impact on risk aversion, via an impact on maths performance, and via an impact on overconfidence. None of these hold up to the data and we conclude that sex hormones have a more direct impact on competitiveness.

The next section describes which variables we use to capture the relevant features of the menstrual cycle and of hormonal contraceptives. Section 3 provides further details about the experimental design, and Section 4 describes the sample. Section 5 presents the basic results and Section 6 reports the findings regarding possible pathways. Section 7 concludes.

\footnotetext{
${ }^{6}$ Contrary to the economic literature, the psychological and medical literature investigating the effects of the menstrual cycle is vast. Hampson and Kimura (1992) and Maki et al. (2002) find that during menstruation when hormone levels are low, women do better at male-oriented tasks such as spatial ability, while doing better at female-oriented tasks such as articulation during high-oestrogen phases. Others have found menstrual cycle effects on a wide range of behaviours and preferences including mood swings (Bäckström et al., 1983), risk taking behaviour (Chavanne and Gallup Jr, 1998), food intake (Gong et al., 1989), visual memory (Phillips and Sherwin, 1992), preferences for male body odour (Thornhill and Gangestad, 1999), preferences for male faces (Penton-Voak et al., 1999), and the likelihood of contracting soccer injuries (Möller-Nielsen and Hammar, 1989).
} 


\section{The menstrual cycle and hormonal contraceptives}

Assuming a regular 28-day cycle, the levels of sex hormones in the female body fluctuate according to the following pattern, while levels of testosterone are virtually constant (see e.g. Richardson, 1992 or Owen, 1975):

- Phase 1: Menstrual phase (days 1-5 of the cycle): secretion of oestrogen and progesterone ceases.

- Phase 2: Follicular phase (days 6-12): large amounts of circulating oestrogen and very little progesterone.

- Phase 3: Peri-ovulatory phase (days 13-15): oestrogen levels show a slight decrease.

- Phase 4: Luteal phase (days 16-23): oestrogen and progesterone are secreted, oestrogen levels reach a second peak.

- Phase 5: Premenstrual phase (days 24-28): both oestrogen and progesterone decline drastically during this phase.

The fluctuations of sex hormones over the menstrual cycle are illustrated in Figure 1. For subjects experiencing a natural menstrual cycle, we construct five binary variables indicating in which phase of the menstrual cycle a subject is situated (assuming a regular 28-day cycle). We also construct two continuous variables representing the expected oestrogen and progesterone levels given the day of the cycle a subject is currently in. ${ }^{7}$ Assuming a regular 28-day cycle can be expected to lead to some measurement error when dividing subjects into the five menstrual cycle phases. However, most of the variability in cycle length between individuals stems from differences in the length of the follicular phase. The length of the ovulatory, luteal, and premenstrual phases on the other hand is relatively fixed (Hampson and Young, 2008). We construct a prospective measure of the menstrual cycle - i.e. we elicit information about the expected beginning of the next menstruation and then count backwards - and the only distinction potentially affected by mis-classification should therefore be the one between the first and second phase. We also ask subjects whether they are currently menstruating or not and use this information to reallocate them between phases one and two, moving all menstruating subjects to phase one and all non-menstruating subjects to phase two. This should eliminate the mis-classifications. Our assessment of expected daily hormone levels should hardly be affected at all as levels of both oestrogen and progesterone are almost constant over the first nine days of the cycle.

\footnotetext{
${ }^{7}$ The average daily urinary hormone levels over the menstrual cycle are obtained from Martin and Behbehani (2006).
} 
In women using hormonal contraceptives such as the pill or vaginal rings, which contain varying levels of artificial oestrogen and progestins ${ }^{8}$, hormonal fluctuations are different. Oestrogen secretion by the body is markedly reduced and progesterone production ceases completely in women taking hormonal contraceptives (Rivera et al., 1999). These contraceptives work by inhibiting ovulation and thickening the cervical mucus so that sperm penetration becomes more difficult. In order to achieve this, they administer constant daily doses of an artificial oestrogen and an artificial progestin. The most common route of administration is the famous "anti-baby pill", which is taken orally once a day. Other products featured in our sample are vaginal rings - elastic rings which give off a constant daily dose of hormones when introduced into the vagina - and contraceptive patches. All these contraceptives have in common that they are subject to a 28-day cycle wherein a 21-day intake period is followed by a 7-day break during which hormonal intake levels drop to zero. During this 7-day break, a withdrawal bleeding, which is not technically a menstruation, can occur, but bleeding is generally much weaker in pill-users and other menstrual phase symptoms such as cramps and mood swings are also less severe.

For hormonal contraceptive users, we construct a binary variable indicating whether a subject is on the 7-day pill break. Given that a 28-day cycle is virtually assured for subjects taking the pill, we do not expect measurement error to be an issue. It might seem attractive at first sight to use the differing strengths of the oestrogen and progestin dosage of various contraceptive brands in order to disentangle the effect of the two hormones but there are a few important caveats. All contraceptives in our sample (and indeed virtually all contraceptives on the market) contain the artificial oestrogen ethinyl estradiol and it is therefore easy to compare contraceptives along the potency of their oestrogen dose which varies between 0.015 and $0.05 \mathrm{mg}$ in our sample. However, comparison with respect to the potency of the progestin intake is markedly more complicated: the hormonal contraceptives currently on the market contain a wide range of progestins with widely different properties. While all of them act like progesterone to a certain extent (this is referred to as their progestational activity) some progestins also act as androgens or anti-androgens. Androgens are hormones which stimulate the emergence and maintenance of masculine characteristics such as body hair growth while antiandrogens are substances suppressing male characteristics by inhibiting the activity of androgens; the best-known androgen is testosterone. While there is a large literature trying to estimate and compare the progestational and androgenic activity of different progestins, generally using rats or rabbits, studies employing a uniform methodology to compare a large number of different progestins using human subjects are hard to come by. ${ }^{9}$

Moreover, the exact contraceptive brand prescribed to an individual - and therefore the dosage of the oestrogen and progestin consumption - may be endogenous with respect to the outcome variable. This

\footnotetext{
${ }^{8} \mathrm{~A}$ progestin is a synthetic hormone that has effects similar to progesterone.

${ }^{9}$ See Muhn et al. (1995) and Kuhnz et al. (1995) for examples of studies using animal models. See Mansour (2006) for a summary of the research on the progestational and androgenic activity of most of the progestins found in currently available hormonal contraceptives
} 
Figure 1: Hormone Levels over the Menstrual Cycle (Adapted from The Merck Manual 2004-2008, Merck \& Co., Inc.)
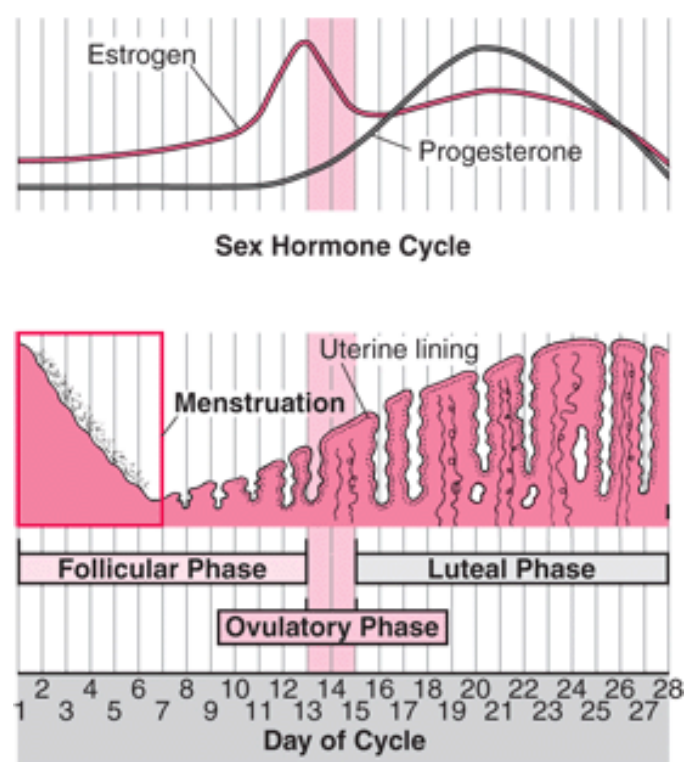

is especially true for the effect of pills with anti-androgenic effects. These pills are given specifically to women suffering from too high a concentration of androgens. Consequently, if androgens enhance competitiveness, as has often been suggested with respect to the androgen testosterone, there will be a spurious positive correlation between the intake of anti-androgens and competitiveness. Similar issues can be expected to persist with respect to the oestrogen dosage of pills. We therefore favour the results stemming from the simple dummy variable which picks up the effect of the average hormonal contraceptive in the sample and which does not suffer from endogeneity issues. For the same reason it is also impossible to compare users of hormonal contraceptives with subjects experiencing a natural cycle. We therefore split our sample into contraceptive users and non-users and run separate analyses.

\section{Experimental design}

Data were collected in a series of lab experiments in which subjects participated in four parts: a part eliciting their attitudes towards risk, a part related to choices regarding competition, a part measuring their social preferences, and a public goods part. Subjects were paid for only one of these four parts, which was randomly determined after the last part was played. This method to determine subjects' payoffs avoids that the different parts are connected through an endowment effect. In this paper, we only report results from the competition and risk attitudes part. Results obtained from the social preferences and public goods parts will be reported in a separate paper.

The design of the competition part closely follows the methodology of Niederle and Vesterlund (2007). Subjects are divided into groups of four and are asked to perform the simple task of solv- 
ing as many sums of five two-digit numbers as they can during a five-minute interval. In a first round, they are compensated according a non-competitive piece rate and in a second round according to a competitive tournament scheme. Being informed about her absolute but not their relative performance, each subject then decides which of the two compensation schemes she wishes to apply in a third round. A random pick of one of the rounds is relevant for payment. This design has the advantage that subjects experience both schemes before making a decision and enables us to determine whether ability has an effect on compensation scheme choice. In the risk part of the experiment, subjects complete a simple lottery choice task which allows us to determine the importance of risk aversion as a determinant of fluctuations in competitiveness. All seven sessions were conducted at the computer lab of CREED (Center for Research in Experimental Economics and Political DecisionMaking) at the University of Amsterdam in the Netherlands. There was a total of 120 subjects, all of which are university students enrolled in various fields. On top of the task-specific compensation detailed below, subjects received a fixed fee of ten Euros. Subjects received task-specific instructions only immediately before the start of each round. The experiment was programmed and conducted with the software z-Tree (Fischbacher, 2007).

Subjects are presented with a randomly drawn sequence of five two-digit numbers which are presented on the screen in a row. Participants then enter their answer into a box and press a button. A new series of numbers appears immediately together with information on whether the previous answer was correct. Subjects are allowed to use scratch paper but no calculators. The total time per round is five minutes and subjects may solve as many sums as possible. Niederle and Vesterlund (2007) find no gender differences in ability for solving these simple arithmetic problems.

During the first round, subjects are compensated according to a piece rate, receiving $1 €$ for each correct answer. In the second round, compensation follows a competitive tournament scheme. The subject with the highest score of each group receives $4 €$ per correct answer while the rest receive nothing. ${ }^{10}$ After each round, subjects are informed about their absolute, but not about their relative performance. In the third round, before performing the five minute maths task once more, subjects decide which compensation scheme, piece-rate or tournament, they would like to apply this time. Subjects going for the tournament receive $4 €$ per correct answer if they score higher than the best of their group mates did in round two. There are several reasons to proceed this way. First, while the performance of a subject opting for competition is still evaluated against performances obtained through a tournament, her beliefs about the decisions of others do not play a role. Second, a subject's choice does not affect the payments of others and social preferences can therefore be excluded as a source of bias. Finally before informing subjects about their payment, we elicit their beliefs about their relative performances in rounds one and two by asking them to estimate their group rank for each task. Subjects receive $2 €$ for each correct guess. This enables us to determine whether (over)confidence plays a role in the choice of compensation scheme.

\footnotetext{
${ }^{10}$ In case there are two or more winners, the money is split equally.
} 
Table 1: Contraceptive Use

\begin{tabular}{lcc}
\hline Contraceptive & Number of Subjects & Percentage \\
\hline Pill & 47 & 43.9 \\
Condoms & 31 & 29.0 \\
Other hormonal contraceptives & 6 & 5.6 \\
Other methods & 1 & 0.9 \\
None & 22 & 20.6 \\
Total & 107 & 100.0 \\
\hline
\end{tabular}

To measure attitudes towards risk, we conducted a simple objective probability lottery choice experiment which follows the methodology of Eckel and Grossman (2002). This will allow us to control for the impact of risk aversion on competitiveness and to test whether the impact of sex hormones on competitiveness is mediated by an impact on risk aversion. Subjects can choose between a sure payoff of 8 Euros and four 50/50 lotteries with linearly increasing riskiness and expected payoffs: $12 / 6,16 / 4,20 / 2,24 / 0$. The choice of lottery then serves as an indicator of the risk aversion of the subject, yielding a discrete variable ranging from 1 (sure thing) to 5 (highest expected payoff/highest risk option). ${ }^{11}$

\section{Sample}

Before being informed about their payment, subjects answer a short questionnaire eliciting details about their menstrual cycle, in particular in how many days their next menstrual cycle will begin and whether they are currently menstruating. The subjects are also asked which kind and brand of contraceptive they use. Finally, we also elicit their age, nationality, and study major.

We drop 13 subjects who state not to experience a menstrual cycle at all. This can be due to a range of factors including the consumption of contraceptives which completely suppress menstruation, ill health, and pregnancy. Of the remaining subjects, 79.4 percent use some kind of contraceptive with 49.5 percent using hormonal methods (see Table 1). 43 out of 53 subjects using hormonal contraceptives remembered the exact brand so that we could obtain information on the content and dosage. The subjects are on average 23.2 years old and 47.7 percent are of Dutch nationality with the rest being mainly of European origin. 42.1 percent of the students have a background in economics which includes students who picked economics, econometrics, business, or finance as their major.

The subjects are randomly assigned to the different parts of the cycle with respect to their age and

\footnotetext{
${ }^{11}$ We also measured risk attitudes through the methodology designed by Holt and Laury (2002). The two risk measures are highly correlated. But since the Holt-Laury measure is a bit more complicated for subjects to grasp - leading some subjects to make inconsistent choices - we only use the results obtained with the Eckel-Grossman methodology in this paper.
} 
Table 2: Subjects by Menstrual Cycle Phase

\begin{tabular}{lcc}
\hline Menstrual Cycle or Pill Cycle Phase & Number of Subjects & Expected Number of Subjects \\
\hline Menstrual Phase (5 days) & 11 & 10 \\
Follicular Phase (7 days) & 15 & 13 \\
Peri-Ovulatory Phase (3 days) & 9 & 6 \\
Luteal Phase (8 days) & 15 & 15 \\
Premenstrual Phase (5 days) & 4 & 10 \\
Pill Break (7 days) & 13 & 13 \\
Pill Intake Phase (21 days) & 40 & 40 \\
\hline
\end{tabular}

nationality: the Kruskal-Wallis equality-of-populations rank test returns a $p$-value of 0.46 for the null hypothesis of no variation in age between subjects assigned to different menstrual cycle phases and a $p$-value of 0.19 with respect to having the Dutch nationality. The same is true for users of hormonal contraceptives when it comes to assignment to the pill break: the Kruskal-Wallis test returns $p$-values of 0.95 with respect to age and of 0.78 with respect to nationality.

Table 2 contains the actual and expected distribution of subjects across menstrual cycle phases and between the pill-intake and pill-break phases. Selective attrition due to menstruating subjects staying away does not seem to be a problem: a $\chi^{2}$-test cannot reject equality of the observed distribution and the theoretical distribution, returning a $p$-value of 0.50 . The same is true for subjects using hormonal contraceptives: the number of subjects on the pill-break, when withdrawal bleedings occur, is exactly equal to the expected number.

This study uses a between subject design. A within subject design, with subjects participating in four consecutive weekly sessions, would have the advantage of catching each subject on different parts of her cycle. There are, however, important caveats which convinced us that a between subject design is preferable. Apart from the obvious problems of attrition and substantially increased costs, it seems likely that subjects would be influenced by their previous choices if playing the same game (or similar games) repeatedly.

\section{Basic results}

Our results show a large and significant effect of female sex hormones on competitiveness. Women experiencing a natural menstrual cycle are significantly less likely to choose the tournament - i.e. significantly less competitive - during the fourth phase of the menstrual cycle when progesterone is being secreted in large quantities and oestrogen secretion is strong too. Making use of the diverging fluctuation patterns of oestrogen and progesterone over the menstrual cycle, we show that this is mainly attributable to the effects of progesterone. Women taking hormonal contraceptives are significantly 
more competitive during the pill break than outside of the pill-break. Keeping in mind that women are generally found to be significantly less competitive than men, we conclude that the behaviour of women shifts towards the behaviour of men when hormone concentrations are low, which confirms the hypothesis of sex hormones being a cause of gender differences in competitiveness.

Non-parametric tests confirm the significance of our results: the Kruskal-Wallis equality-of-populations rank test returns a $p$-value of 0.08 for the null-hypothesis of equality of competitiveness across the five phases of the menstrual cycle and a $p$-value of 0.04 for the null of equality between the 7-day pill-break and the rest of the 28-day pill-cycle.

Average performance is in line with the findings of Niederle and Vesterlund (2007). The mean number of correct answers is 9.6 in round one and 11.5 in round two, the difference between the rounds being significant $(p<0.01$; one-sided $t$-test). This difference can be due either to learning effects or to the effect of increased competition on effort. Given that we observe a further significant increase from the second to the third round even for those subjects choosing the piece rate $(p<0.01)$, there is more support for the hypothesis that learning effects are at play. The proportion of subjects opting for competition in round three is 44.9 percent. ${ }^{12}$ Subjects choosing to enter the tournament perform better than the rest neither in round one $(p=0.46)$ nor in round two $(p=0.32)$.

Table 3 contains the results for linear probability models estimating the impact of different phases of the menstrual cycle on competitiveness for specifications without and with control variables. ${ }^{13}$ These results show that for subjects experiencing a natural menstrual cycle, the likelihood of self-selecting into the competitive environment fluctuates strongly and significantly over the menstrual cycle. Competitiveness is significantly lower during the fourth phase (luteal phase) of the menstrual cycle than during each the first, third and fifth phases, all of which are characterised by relatively low hormone levels, and these differences are significant at the five percent level for all specifications. The significance of the gap in competitiveness between the fourth phase and the rest of the cycle is confirmed by the Kruskal-Wallis test ( $p$-value: 0.02 ) and the one-sided $t$-test ( $p$-value: 0.01 ). The luteal phase is the only phase during which progesterone is secreted in large quantities, while at the same time oestrogen secretion reaches a second peak, so that combined hormone concentration is particularly high. At roughly 44 percent, the difference in the likelihood of competing between the fourth phase and the first phase, for example, is very large and roughly equal to the gender gap discovered by Niederle and Vesterlund (2007). Moreover, there is a positive spike in competitiveness in the fifth phase, during which hormone secretion drops drastically, but the significance of the difference between the first and the fifth phase does not withstand the inclusion of controls.

In Table 4, we replace the menstrual cycle dummies by daily average oestrogen and progesterone

\footnotetext{
${ }^{12}$ At 44.9 percent, the proportion of female participants opting for competition is slightly higher than in previous studies using a mixed cohort. This is consistent with the finding of Booth and Nolen (2009a) that being in an all female group for a mere twenty minutes makes it more likely for women to compete relative to women being part of a mixed group.

${ }^{13}$ Probit and logit estimation returns very similar results.
} 
Table 3: The Effect of Natural Hormone Fluctuations on Competitiveness

(1)

(2)

(3)

Competitiveness

Cycle Phase 1

Cycle Phase 2

Cycle Phase 3

Cycle Phase 4

Cycle Phase 5

Controls for demographics

Controls for risk aversion

and maths scores (rounds 1 and 2)

Observations

R-squared reference

$\begin{array}{ccc}-0.012 & -0.128 & -0.147 \\ (0.208) & (0.224) & (0.231) \\ 0.121 & 0.066 & 0.0257 \\ (0.228) & (0.241) & (0.247) \\ -0.279 & -0.432 * * & -0.439 * * \\ (0.198) & (0.188) & (0.194) \\ 0.455 * * * & 0.323 * & 0.305 \\ (0.158) & (0.186) & (0.192)\end{array}$

no

yes

yes

no

no

yes

Table 4: The Effect of Natural Hormone Fluctuations on Competitiveness

(1)

(2)

(3)

Competitiveness

\begin{tabular}{|c|c|c|c|}
\hline \multirow[t]{2}{*}{ Natural Oestrogen } & 0.011 & 0.012 & 0.011 \\
\hline & $(0.007)$ & $(0.008)$ & $(0.008)$ \\
\hline \multirow[t]{2}{*}{ Natural Progesterone } & $-0.038 * *$ & $-0.046 * * *$ & $-0.044 * * *$ \\
\hline & $(0.016)$ & $(0.018)$ & $(0.013)$ \\
\hline Controls for demographics & no & yes & yes \\
\hline $\begin{array}{l}\text { Controls for risk aversion } \\
\text { and maths scores (rounds } 1 \text { and 2) }\end{array}$ & no & no & yes \\
\hline Observations & 54 & 54 & 54 \\
\hline R-squared & 0.092 & 0.252 & 0.260 \\
\hline
\end{tabular}

Robust standard errors in parentheses; *** $\mathrm{p}<0.01$, ** $\mathrm{p}<0.05, * \mathrm{p}<0.1$ 
Competitiveness

Pill Break

Hormonal Contraceptives

Controls for demographics

Controls for risk aversion

and maths scores (rounds 1 and 2)

Observations

R-squared
$-0.315^{* *}$

(0.156)

no

no

53

0.078 reference

$-0.321 *$

$-0.258^{*}$

(0.166)

$(0.143)$

yes

yes

Robust standard errors in parentheses; $* * * \mathrm{p}<0.01, * * \mathrm{p}<0.05, * \mathrm{p}<0.1$

levels. We can see that while the effect of progesterone fluctuations is highly significant and negative, the effect of oestrogen is insignificant. This indicates that the fluctuations in competitiveness over the menstrual cycle are mainly due to the effects of progesterone.

Table 5 shows the results for subjects using hormonal contraceptives. Women in this group are significantly more competitive during the pill-break than during the rest of the cycle and at 26 to 32 percentage points this effect is large. As the effects of natural hormonal fluctuations, the effect of hormonal contraceptives is robust across specifications.

It is important to note that the results obtained for the subjects taking hormonal contraceptives and for those experiencing a natural cycle point in the same direction. The slump in competitiveness during the luteal phase is similar in magnitude to the negative effect of hormonal contraceptives. The gender gap in competitive behaviour thus widens during times of high concentration of female sex hormones, especially of progesterone, and the magnitudes of both the effect of natural hormonal fluctuations and of the fluctuations induced by hormonal contraceptives are substantial. Multiplying the estimated effects for menstrual cycle phases two to five with the expected fraction of days a woman spends in each phase over an average 28-day cycle, we find that women are 10.5 percentage points less competitive compared to a fictitious situation in which sex hormones are always at the low levels observed during the menstrual phase. This back-of-the-envelope calculation indicates that the effect of hormones can account for roughly a quarter of the gender gap in competitiveness estimated by Niederle and Vesterlund (2007). This confirms that hormonal differences between men and women provide a compelling partial biological explanation for observed gender differences in competitiveness. 


\section{Possible pathways}

Our results show that female sex hormones have a significant impact on competitiveness. We will now investigate whether this effect is direct or whether it is mediated by an impact on one of several possible determinants of competitiveness. We consider three possible pathways for the impact of sex hormones: via an impact on risk aversion, via an impact on mathematical abilities, and via an impact on overconfidence. None of these hypotheses hold up to the data and we conclude that sex hormones must have a more direct impact on competitiveness.

\subsection{Risk aversion}

Chen et al. (2005) hypothesise that the impact of the menstrual cycle on auction bids is mediated by an impact on risk aversion and Datta Gupta et al. (2005) show that women are strongly influenced by their degree of risk aversion when deciding whether to compete or not. Moreover, there is a long list of studies, including Eckel and Grossman (2002) and Powell and Ansic (1997), showing that women are significantly more risk averse than men. ${ }^{14}$ The hypothesis that the impact of sex hormones on competitiveness is mediated by an impact on risk aversion seems therefore plausible.

Risk aversion as measured by our lottery choice experiment is indeed a strong and significant predictor of tournament entry. The Kruskal-Wallis test for equality of competitiveness across individuals with varying levels of risk aversion returns a $p$-value of 0.01 . This is confirmed by regressions results: the coefficient on risk aversion is significant at the one percent level (regression results are not reported). An increase of one (on a five-point scale) in our risk aversion indicator leads to an increase in the likelihood of competing of around ten percentage points.

But the second link in the chain, namely an impact of hormones on risk aversion, is missing. The Kruskal-Wallis test returns a $p$-value of 0.79 for equality of risk aversion across the menstrual cycle phases and a $p$-value of 0.18 for equality between the pill-intake phase and the pill-break. The regression results in Columns (1) and (2) of Table 6 show the same picture. The differences in risk aversion between the different menstrual cycle phases are small in magnitude and insignificant. The difference in risk aversion between subjects in the first phase and subjects in the fourth phase is virtually zero and can therefore not explain the large difference in competitiveness between these phases. The coefficient on contraceptive intake is equally insignificant and, although somewhat larger in magnitude than most of the differences between cycle phases, too small to explain much of the variation in competitiveness between the pill-break and the pill-intake phase. We conclude that an effect of sex hormones on risk aversion does not represent a significant pathway for the impact of these hormones on competitiveness.

\footnotetext{
${ }^{14}$ See Croson and Gneezy (2009) for a full survey of studies investigating gender differences in risk attitudes. The vast majority of surveyed papers find that women are more risk averse than men.
} 
Table 6: The Effect of Natural Hormone Fluctuations and Hormonal Contraceptives on Potential Determinants of Competitiveness

\begin{tabular}{|c|c|c|c|c|c|c|c|c|}
\hline \multirow[b]{2}{*}{ Dependent Variable } & (1) & (2) & (3) & (4) & (5) & (6) & (7) & (8) \\
\hline & \multicolumn{2}{|c|}{ Risk Aversion } & \multicolumn{2}{|c|}{ Mean Score } & \multicolumn{2}{|c|}{ High Rank Guess } & \multicolumn{2}{|c|}{ Overestimation } \\
\hline \multirow[t]{2}{*}{ Cycle Phase 2} & 0.120 & & 1.288 & & -0.134 & & -0.015 & \\
\hline & $(0.635)$ & & $(2.298)$ & & $(0.224)$ & & $(0.234)$ & \\
\hline \multirow[t]{2}{*}{ Cycle Phase 3} & 0.377 & & 2.009 & & -0.190 & & -0.196 & \\
\hline & $(0.626)$ & & $(2.421)$ & & $(0.224)$ & & $(0.248)$ & \\
\hline \multirow[t]{2}{*}{ Cycle Phase 4} & 0.009 & & 0.813 & & 0.001 & & -0.051 & \\
\hline & $(0.583)$ & & $(2.295)$ & & $(0.175)$ & & $(0.245)$ & \\
\hline \multirow[t]{2}{*}{ Cycle Phase 5} & 0.716 & & 0.252 & & 0.085 & & 0.256 & \\
\hline & $(1.016)$ & & $(2.618)$ & & $(0.194)$ & & $(0.298)$ & \\
\hline Hormonal & & -0.588 & & -1.490 & & -0.041 & & 0.065 \\
\hline Contraceptives & & $(0.446)$ & & $(1.152)$ & & $(0.157)$ & & $(0.146)$ \\
\hline Controls for demographics & yes & yes & yes & yes & yes & yes & yes & yes \\
\hline Control for round two score & no & no & no & no & yes & yes & yes & yes \\
\hline Observations & 54 & 53 & 54 & 53 & 54 & 53 & 54 & 53 \\
\hline R-squared & 0.136 & 0.097 & 0.099 & 0.257 & 0.399 & 0.129 & 0.212 & 0.181 \\
\hline
\end{tabular}

Robust standard errors in parentheses; *** $\mathrm{p}<0.01, * * \mathrm{p}<0.05, * \mathrm{p}<0.1$ 


\subsection{Mathematical ability}

Given that the psychological literature has found some cognitive functions to vary over the menstrual cycle $^{15}$, one could imagine that the same is true for the ability to solve sums. If mathematical ability was significantly lower in times of high concentration of sex hormones, this could obviously have a negative impact on subjects' readiness to compete. But this hypothesis does not hold up on two accounts. On the one hand, there is no significant impact of sex hormones on average maths scores and, on the other hand, the performance of a subject in rounds one and two has no influence on her decision of whether or not to compete in round three.

The Kruskal-Wallis test returns a $p$-value of 0.83 for the null of no variation in arithmetic performance over the menstrual cycle. Also, the regression in Column (3) of Table 6 shows that none of the cycle coefficients is significant and that average performance is actually higher for subjects in the fourth phase than for subjects in the first and fifth. The difference between the pill-break and the pill-intake phase is marginally significant with a Kruskal-Wallis $p$-value of 0.10 but this effect does not withstand the inclusion of controls as can be seen in Column (4) of Table 6.

Moreover, absolute performance in rounds one and two, which is all the information subjects have at the moment of making the decision of whether or not to enter the tournament at the start of round three, has no impact on competitiveness. The regression results in Table 7 show that the effect of the mean score from rounds one and two on the likelihood of competing in round three is both insignificant and negligibly small. Other measures of performance yield the same result when added as regressors (regression results are not reported): scores from round two only and group ranks in rounds one and two are not significant in any specification when used to replace actual performance. The same is true for dummies indicating an individual was the best or amongst the two best of his group. The KruskalWallis $p$-values for equality in competitiveness across individuals of differing group ranks are 0.74 for round one ranks and 0.62 for round two ranks. We conclude that the impact of sex hormones on competitiveness is not mediated via an impact on mathematical abilities.

\subsection{Overconfidence}

Niederle and Vesterlund (2007) find that (over)confidence plays a significant but limited role in explaining whether an individual chooses to compete. In their experiment, men are significantly more overconfident than women and this gender gap in overconfidence can explain about a quarter of the gender gap in competitiveness. We will therefore test the hypothesis that the gender gap in overconfidence is related to differences in the hormonal balance and that this could be a mechanism by which hormonal fluctuations affect competitiveness.

\footnotetext{
${ }^{15}$ See for example the above-mentioned Hampson and Kimura (1992) and Maki et al. (2002). Epting and Overman (1998), on the other hand, find no performance fluctuations using a wide array of cognitive tasks.
} 
Competitiveness

Mean Score (Rounds 1 and 2)

0.004

(0.013)

no

Controls

Controls for cycle and contraceptives

Observations

R-squared
107

0.001
0.011

(0.013)

yes

no

107

0.186
0.007

yes

yes

107

0.295

We use the beliefs of the subjects about their own rank in rounds one and two of the arithmetics task in order to test this hypothesis. We find some evidence that differences in confidence are related to tournament entry. Subjects are clearly overestimating their own performance in the round two tournament: 67 percent believe to be either first or second amongst their group mates. Also, 41 percent of subjects overestimate their rank while only 21 percent underestimate their relative performance. A one-sided $t$-test indicates that individuals who belief that they are amongst the two best in their group in round two (the tournament round) are 16 percent more likely to enter the tournament in round three ( $p$-value: 0.06 ) and that subjects who overestimate their performance in round two are 13 percent more likely to compete ( $p$-value: 0.10 ) than the rest. ${ }^{16}$ When added as regressors in a linear probability model with tournament entry as the dependent variable, the binary variable indicating that a subject beliefs to be amongst the two best of her group is significant at the ten percent level while the overconfidence dummy is not significant (regression results not reported).

The regression results in Columns (5) to (8) of Table 6 make clear that an effect of sex hormones on overconfidence cannot be a pathway by which hormonal fluctuations affect competitiveness. Conditional on absolute performance in round two, neither the menstrual cycle phase dummies nor the contraceptive intake dummy significantly affect the beliefs that subjects hold about their own performance. ${ }^{17}$ These results are confirmed by non-parametric test results. The Kruskal-Wallis $p$-values for the null of no variation over the menstrual cycle are 0.59 for the belief of being amongst the top two of one's group and 0.51 for the likelihood of overestimating one's rank. The picture is the same for variation caused by hormonal contraceptives with $p$-values of 0.34 and 0.55 respectively.

\footnotetext{
${ }^{16}$ No such effects can be found for overconfidence and beliefs concerning performance in round one (the piece-rate task).

${ }^{17}$ Results do not change when not controlling for round two performance.
} 


\section{Conclusions}

The labour market decisions of men and women are strikingly different, especially when it comes to the competitiveness of the chosen work environment. Simply put, men seem to actively seek competition while women tend to avoid it - a fact that is corroborated by several controlled experiments in the lab. This difference is very likely one of the causes of the gender gap in wages, especially since the gender wage gap has been shown to be increasing across the wages distribution (Arulampalam et al., 2007) and thus to be highest for those positions where competition is especially fierce. It is therefore an important question whether these differences are purely a consequence of upbringing and education or whether biological differences between the women and men play a role as well. Which policies we should adopt if we wish to tackle the gender imbalances in the labour market crucially depends on whether nature or nurture is at play.

Our results point towards female sex hormones playing an important part in explaining gender differences in competitiveness. Women are significantly less competitive both when taking contraceptives containing oestrogen and progesterone and during the parts of the menstrual cycle when secretion of these hormones is especially strong. Taking advantage of the differing fluctuation patterns of oestrogen and progesterone, we show that it is mainly progesterone which causes the variations in competitiveness over the menstrual cycle. These effects are strong enough to explain a substantial part of the gender gap in competitiveness observed in previous lab experiments. We also find that the impact of hormones on competitiveness is mediated neither by an effect of sex hormones on risk aversion, nor by an effect on overconfidence or performance.

This shows that next to the cultural factors identified by Gneezy et al. (2008) amongst others, biological factors play an important role in explaining gender differences in competitiveness. An interesting direction for future research could be to directly measure the concentration of hormones in the body of subjects by taking blood or urine samples. Alternatively, although this would certainly make matters more complicated, a placebo controlled trial with subjects being administered doses of oestrogen, progesterone, or testosterone could be a logical next step. Closer attention to progesterone seems particularly warranted. This hormone has so far been largely ignored in the literature on the effects of hormones on economic decision making but our results suggest the possibility that it could play an important role in explaining gender differences in other areas as well. Future experiments could also look at the link between testosterone and competitiveness. Sapienza et al. (2009) find that testosterone levels influence career choice and conclude that this effect works through an impact on risk preferences. Given our results, it is plausible that an effect of testosterone on competitiveness could be another pathway by which testosterone levels are correlated with career decisions. Further research into the exact mechanisms underlying the hormonal effects on competitiveness also seems warranted. This includes the open question of whether it is the preferences of individuals or rather their perceptions of competitive situations which are influenced by hormones. 


\section{References}

Apicella, Coren L., Anna Dreber, Benjamin Campbell, Peter B. Gray, Moshe Hoffman, and Anthony C. Little, "Testosterone and financial risk preferences," Evolution and Human Behavior, 2008, 29, 384-390.

Arulampalam, Wiji, Alison L. Booth, and Mark L. Bryan, "Is There a Glass Ceiling over Europe? Exploring the Gender Pay Gap across the Wage Distribution," Industrial and Labor Relations Review, 2007, 60 (2), 163-186.

Baumgartner, Thomas, Markus Heinrichs, Aline Vonlanthen, Urs Fischbacher, and Ernst Fehr, "Oxytocin Shapes the Neural Circuitry of Trust and Trust Adaptation in Humans.," Neuron, 2008, 58 (4), 639-650.

Bäckström, Torbjorn, Diana Sanders, Rosemary Leask, David Davidson, Pamela Warner, and John Bancroft, "Mood, sexuality, hormones, and the menstrual cycle. Hormone levels and their relationship to the premenstrual syndrome.," Psychosomatic Medicine, 1983, 45 (6), 503-507.

Bertrand, Marianne and Kevin F. Hallock, "The Gender gap in top corporate jobs," Industrial and Labor Relations Review, 2001, 55 (1), 3-21.

Booth, Alison L. and Patrick J. Nolen, "Choosing to Compete: How Different Are Girls and Boys?," IZA Discussion Papers 4027, Institute for the Study of Labor (IZA) 2009.

_ and _ , "Gender Differences in Risk Behaviour: Does Nurture Matter?," IZA Discussion Papers 4026, Institute for the Study of Labor (IZA) 2009.

Burnham, Terence C., "High-testosterone men reject low ultimatum game offers.," Proceedings of the Royal Society, 2007, 274, 2327-2330.

Carmichael, Marie S., Valerie Warburton, Jean Dixen, and Julian M. Davidson, "Relationships Among Cardiovascular, Muscular, and Oxytocin Responses During Human Sexual Activity.," Archives of Sexual Behavior, 1994, 23 (1), 59-79.

Chavanne, Tara J. and Gordon G. Gallup Jr, "Variation in Risk Taking Behavior Among Female College Students as a Function of the Menstrual Cycle.," Evolution and Human Behavior, 1998, $19(1), 27-32$.

Chen, Yan, Peter Katuscak, and Emre Ozdenoren, "Why Can't a Woman Bid More Like a Man?," CERGE-EI Working Papers wp275, The Center for Economic Research and Graduate Education Economic Institute, Prague 2005. 
_, , and _ , "Sealed bid auctions with ambiguity: Theory and experiments," Journal of Economic Theory, 2007, 136 (1), 513-535.

_ ,_, and _ , "Why Can’t a Woman Bid More Like a Man?," 2009.

Croson, Rachel and Uri Gneezy, "Gender differences in preferences," Journal of Economic Literature, 2009, 47 (2), 448-74.

Eckel, Catherine C. and Philip J. Grossman, "Sex Differences and Statistical Stereotyping in Attitudes toward Financial Risk.," Evolution and Human Behavior, 2002, 23 (4), 281-95.

Epting, L. Kimberly and William H. Overman, "Sex-sensitive tasks in men and women: a search for performance fluctuations across the Menstrual Cycle," Behavioral Neuroscience, 1998, 112 (6), 1304-1317.

Fehr, Ernst, "On The Economics and Biology of Trust," Journal of the European Economic Association, 2009, 7 (2-3), 235-266.

Fischbacher, Urs, “z-Tree: Zurich toolbox for ready-made economic experiments," Experimental Economics, 2007, 10 (2), 171-178.

Gneezy, Uri, Kenneth L. Leonard, and John A. List, "Gender Differences in Competition: Evidence from a Matrilineal and a Patriarchal Society," NBER Working Papers, National Bureau of Economic Research 2008.

_, Muriel Niederle, and Aldo Rustichini, "Performance In Competitive Environments: Gender Differences," The Quarterly Journal of Economics, 2003, 118 (3), 1049-1074.

Gong, Elizabeth J., Dominique Garrel, and Doris Howes Calloway, "Menstrual cycle and voluntary food intake," American Journal of Clinical Nutrition, 1989, 49, 252-258.

Gupta, Nabanita Datta, Anders Poulsen, and Marie-Claire Villeval, "Male and Female Competitive Behavior: Experimental Evidence," IZA Discussion Papers 1833, Institute for the Study of Labor (IZA) 2005.

Hampson, Elizabeth and Doreen Kimura, "Sex Differences and Hormonal Influences on Cognitive Function in Humans," in Jill B. Becker, S. Marc Breedlove, and David Crews, eds., Behavioral Endocrinology, MIT Press, 1992, pp. 357-398.

_ and Elizabeth A. Young, "Methodological issues in the study of hormone-behavior relations in humans: Understanding and monitoring the menstrual cycle," in Jill B. Becker, Karen J. Berkley, Nori Geary, Elizabeth Hampson, James P. Herman, and Elizabeth Young, eds., Sex differences in the brain. From genes to behavior., Oxford University Press, 2008, pp. 63-78. 
Holt, Charles A. and Susan K. Laury, "Risk Aversion and Incentive Effects," American Economic Review, 2002, 92 (5), 1644-1655.

Kosfeld, Michael, Markus Heinrichs, Paul J. Zak, Urs Fischbacher, and Ernst Fehr, "Oxytocin increases trust in humans.," Nature, 2005, 435 (2), 673-676.

Kuhnz, Wilhelm, Karl-Heinrich Fritzemeier, Christa Hegele-Hartung, and Rolf Krattenmacher, "Comparative Progestational Activity of Norgestimate, Levonorgestrel-Oxime and Levonorgestrel in the Rat and Binding of these Compounds to the Progesterone Receptor.," Contraception, 1995, (51), 131-139.

Maki, Pauline M., Jill B. Rich, and R. Shayna Rosenbaum, "Implicit memory varies across the menstrual cycle: estrogen effects in young women," Neuropsychologia, 2002, 40, 518-529.

Mansour, Diana, "Use of the new progestogens in contraception and gynaecology.," The Obstetrician \& Gynaecologist, 2006, (8), 229-234.

Martin, Vincent T. and Michael Behbehani, "Ovarian Hormones and Migraine Headache: Understanding Mechanisms and Pathogenesis-Part 2,” Headache, 2006, 46 (3), 365-386.

Möller-Nielsen, Jesper and Mats Hammar, "Women's soccer injuries in relation to the menstrual cycle and oral contraceptive use.," Medicine \& Science in Sports \& Exercise, 1989, 21 (2), 126129.

Muhn, Peter, Rolf Krattenmacher, Sybille Beier, Walter Elger, and Ekkehard Schillinger, "Drospirenone: A Novel Progestogen with Antimineralocorticoid and Antiandrogenic Activity. Pharmacological Characterization in Animal Models.," Contraception, 1995, (51), 99-110.

Niederle, Muriel and Lise Vesterlund, "Do Women Shy Away from Competition? Do Men Compete Too Much?," The Quarterly Journal of Economics, 2007, 122 (3), 1067-1101.

Owen, John A., "Physiology of the menstrual cycle.," American Journal of Clinical Nutrition, 1975, 28, 333-338.

Pearson, Matthew and Burkhard C Schipper, "Menstrual cycle and competitive bidding," Technical Report 16784, University Library of Munich, Germany 2009.

Penton-Voak, I. S., D. I. Perrett, D. L. Castles, T. Kobayashi, D. M. Burr, L. K. Murray, and R. Minamisawa, "Menstrual cycle alters face preference," Nature, 1999, (6738), 741-742.

Phillips, Susana M. and Barbara B. Sherwin, "Variations in memory function and sex steroid hormones across the menstrual cycle.," Psychoneuroendocrinology, 1992, pp. 497-506. 
Powell, Melanie and David Ansic, "Gender differences in risk behaviour in financial decisionmaking: An experimental analysis," Journal of Economic Psychology, 1997, 18 (6), 605-628.

Richardson, John T.E., “The Menstrual Cycle, Cognition, and Paramenstrual Symptomatology,” in John T.E. Richardson, ed., Cognition and the Menstrual Cycle, Springer-Verlag, 1992.

Rivera, Roberto, Irene Yacobson, and David Grimes, "The mechanism of action of hormonal contraceptives and intrauterine contraceptive devices.," American Journal of Obstetrics \& Gynecology, 1999, 181, 1263-1269.

Sapienza, Paola, Luigi Zingales, and Dario Maestripieri, "Gender differences in financial risk aversion and career choices are affected by testosterone," Proceedings of the National Academy of Sciences, 2009.

Thornhill, Randy and Steven W. Gangestad, "The Scent of Symmetry: A Human Sex Pheromone that Signals Fitness?," Evolution and Human Behavior, 1999, 20 (3), 175-201.

Uvnäs-Moberg, Kerstin, "Oxytocin may mediate the benefits of positive social interaction and emotions.," Psychoneuroendocrinology, 1998, 23 (8), 819-835.

Zethraeus, Niklas, Ljiljana Kocoska-Maras, Tore Ellingsen, Bo von Schoultz, Angelica Linden Hirschberg, and Magnus Johannesson, "A randomized trial of the effect of estrogen and testosterone on economic behavior," PNAS, 2009, 106, 6535-6538. 